\title{
Composite coatings with nickel matrix and graphene as dispersed phase
}

\author{
Anna Gajewska-Midziałek \\ Institute of Precision Mechanics, ul. Duchnicka 3, 01-796 Warsaw, Poland \\ "Corresponding author: e-mail: anna.gajewska@imp.edu.pl
}

\begin{abstract}
The paper presents the results of the studies of nickel-graphene composite coatings deposited by the electrochemical reduction method. A bath with low concentration of nickel ions, graphene as dispersed particles and organic compounds were used for deposition of the composite coatings nickel-graphene. The results of investigations of coatings deposited from the electrolyte containing $0.33,0.5$ and $1 \mathrm{~g} / \mathrm{dm}^{3}$ graphene and two surface-active compounds were shown. The particles content in the coatings, the surface morphology, the cross-sectional structures of the coated samples, thickness and internal stresses were measured. Voltammetric method was used for examination of the corrosion resistance of samples of composite coatings in $0.5 \mathrm{M} \mathrm{NaCl}$ solution. The obtained results suggest that the content of incorporated graphene particles increases with an increasing amount of graphene in plating bath. The applications of organic addition agents was advantageous because it caused compressive stresses in the coatings. All of the nickel-graphene composite coatings had better corrosion resistance than the nickel coatings.
\end{abstract}

Keywords: nickel, graphene, electrodeposition, composite coatings.

\section{INTRODUCTION}

Composite electrochemical coatings appear to be a very promising and rapidly developing group of coatings generating a great interest, both in research work and in practical applications.

Properties of composite coatings depend on many factors such as the metallic matrix type, dispersed solid phase particle characteristics (type, shape, size, and content), parameters ( $\mathrm{pH}$, temperature, current density and hydrodynamic conditions), bath composition (concentrations, presence of surfactants and additives) ${ }^{1}$.

Nickel matrix composite coatings are used especially in the automotive and aerospace industries due to their very good mechanical properties and corrosion resistance.

Several authors ${ }^{2-5}$ have described the preparation of composite coatings with variety particles and enhanced mechanical properties compared to nickel coatings.

Corrosion and wear often combine to cause aggressive damage in a number of industries such as mining, chemical processing, paper production or energy production. A nickel coating increase of corrosion resistance may be achieved by the incorporation of dispersions like, $\mathrm{SiC}^{6-8}, \mathrm{Al}_{2} \mathrm{O}_{3}{ }^{9}$.

Graphene is a material that has recently become very popular with both the representatives of the scientific world and the media as it gives hope for various uses. Graphene, a single-layer of carbon sheet, exhibits excellent electronic conductivity and optical transmittance with great potential to replace metals as transparent electrodes ${ }^{10}$. Graphene has been considered as a promising material for photodetectors ${ }^{10-12}$. Photodetectors as a class of optoelectronics device have been widely employed in diverse fields, including spectroscopy, telecommunication, astronomy, agriculture, pharmaceuticals, and environmental monitoring ${ }^{12}$. A photodetector based on van der Waals heterostructures of graphene and its fluorine-functionalized derivative is presented by $\mathrm{Du}$ et al. ${ }^{12}$. Wan et al. ${ }^{10}$ present a self-powered, high-performance graphene-enhanced ultraviolet silicon Schottky photodetector. Shehzad et al. ${ }^{13}$ reported a sensitive, low-power consuming, multimode environmental sensor based on grapheme-silicon heterojunction.

The range one of potential applications of graphene is found in materials engineering especially in durable composite materials. It is also possible to use graphene in the form of composites in the aerospace and automotive industries and due to its high strength, ductility and tightness of covering as a layer - in the form of laminated composites, modifying the substrate by improving its resistance to an aggressive environment of exploitation and oxygen corrosion.

Several authors have codeposited a graphene with $\mathrm{Ni}$ matrix. The electrodeposited nickel-graphene composite coating produced by Wang et al. ${ }^{14}$ featured good catalytic properties during an urea oxidation reaction in a $1 \mathrm{M}$ $\mathrm{KOH}$ solution. It can be potentially used as a catalyst in the production of hydrogen and in fuel cells.

Nickel-graphene composite coatings were deposited from a sulfamate electrolyte by Kuang et al. ${ }^{15}$. The composite coating created in this way had a greater hardness and better heat conductivity than a nickel coating.

Kumar et al. ${ }^{16}$ and Jiang et al. ${ }^{17}$ proved that the deposited coating nickel-graphene had also better hardness and corrosion resistance than a nickel coating. Graphene particles changed the orientation of the nickel matrix from (220) to (200) and caused a reduction of this matrix grains from 30 to $20 \mathrm{~nm}$. The refinement of the matrix grain and the incorporation of graphene particles resulted in an increase of the coating microhardness by $100 \mathrm{HV}$. The corrosion rate of the composite coating was two and half times smaller than the corrosion rate of a nickel coating ${ }^{16}$.

Graphene nanosheets with multilayer structures were incorporated into a Ni matrix through a plating process with using a surfactant. With the addition of graphene content as low as $0.05 \mathrm{~g} / \mathrm{dm}^{3}$, hardness of the Ni-graphene composites reached 4.6 GPa, which was about 1.2 times higher that the pure $\mathrm{Ni}$ deposited under the same condition. The enhancement in mechanical properties of the composites is attributed to the preferred formation of the Ni crystalline phases in its (111) plane, the high interaction between $\mathrm{Ni}$ and graphene and the 
prevention of the dislocation sliding in the $\mathrm{Ni}$ matrix by the graphene ${ }^{\mathbf{1 8}}$.

Jabbar et al. ${ }^{19}$ studied the effect of temperature on electrochemical deposition of nickel-graphene composite coating. The coatings deposited at $45^{\circ} \mathrm{C}$ exhibited coarser surface morphology with increased carbon content, refined grain sizes, high micro hardness and better corrosion resistance performance. The introduction of graphene nanosheets in $\mathrm{Ni}$ deposition greatly alter the pattern of preferred crystal orientation and growth behavior. This was attributed to decrease in the grain size of nikel matrix due to incorporating the graphene into nickel matrix and blocking the $\mathrm{Ni}$ crystal growth ${ }^{\mathbf{1 9}}$.

Huang et al. ${ }^{20}$ also conducted research on a composite material in which graphene is used as a dispersion phase ${ }^{\mathbf{2 0}}$.

The aim of this work was the investigation of the effect of surface-active substances added to the nickel plating bath on the properties of electrodeposited nickel-graphene composite coatings.

\section{EXPERIMENTAL}

\section{Characteristic of dispersion phase}

Dispersion particles used in this experiment were Grafen-iGP2 by Grafen Chemical Industries Co., with a diameter of $5 \mathrm{~mm}$, a thickness of 5-8 $\mathrm{nm}$ and a surface area of $120-150 \mathrm{~m}^{2} / \mathrm{g}$ (www.grafen.com.tr) in the amount $0.33,0.5$ and $1 \mathrm{~g} / \mathrm{dm}^{3}$.

The Raman spectrum of graphene particles is shown in Figure 1 where the D peak $\left(1350 \mathrm{~cm}^{-1}\right), \mathrm{G}$ peak $(1600$ $\left.\mathrm{cm}^{-1}\right)$ and 2D peak $\left(2700 \mathrm{~cm}^{-1}\right)$ can be observed. The Raman spectrum is characteristic for multilayer graphene which suggests the 2D peak shape. The spectra indicated a high quality $\mathrm{sp}^{2}$ carbon network with $\mathrm{I}_{\mathrm{D}} / \mathrm{I}_{\mathrm{G}}$ ratio of 0.24 . The presence of some defects in graphene structure is indicated by the small peak $\mathrm{D}^{\mathbf{2 1 - 2 3}}$.

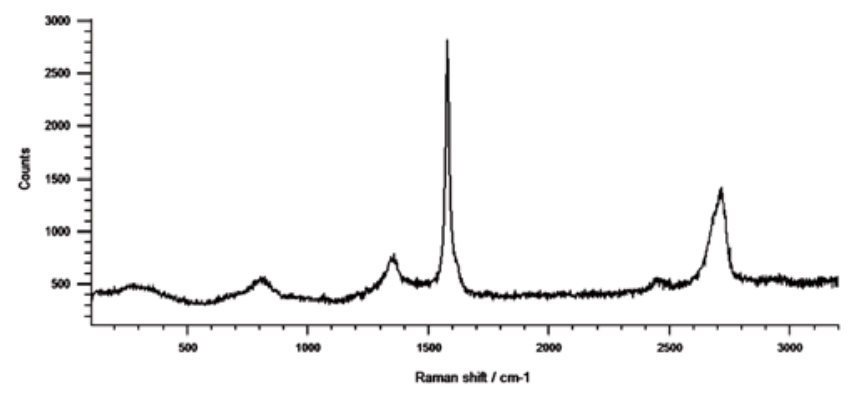

Figure 1. The Raman spectra of IGP2 graphene particles

\section{Deposition process}

The nickel and nickel-graphene electrodeposition were carried-out on 85 x 65 x $1 \mathrm{~mm}$ copper sheets using a low-concentration Watts nickel plating bath. The composition of the nickel bath is given in Table 1 . The Watts solutions are widely used and content of the basic constituents: nickel sulfate, nickel chloride and boric acid. Nickel sulfate is the principal source of nickel ions during the process of electrolysis. When current flows, divalent

Table 1. Composition of the nickel bath

\begin{tabular}{|l|c|}
\hline Component & Concentration \\
\hline $\mathrm{NiSO}_{4} \cdot 7 \mathrm{H}_{2} \mathrm{O}$ & $0.45 \mathrm{M}$ \\
\hline $\mathrm{NiCl}_{2} \cdot 6 \mathrm{H}_{2} \mathrm{O}$ & $0.30 \mathrm{M}$ \\
\hline $\mathrm{H}_{3} \mathrm{BO}_{3}$ & $0.85 \mathrm{M}$ \\
\hline Graphene iGP2 & $0.33 ; 0.5,1 \mathrm{~g} / \mathrm{dm}^{3}$ \\
\hline
\end{tabular}

nickel ions react with two electrons and are converted to metallic nickel at the cathode. Nickel chloride improves anode dissolution and increases solution conductivity. The wide variations in the concentrations of nickel sulfate and nickel chloride are possible. Decrease of all salt concentrations is advantageous both for economy and ecology reasons. The low concentration Watts type Nikel plating bath was developed in the Institute of Precision Mechanics. The bath was prepared with reactants ,pure for analytical purposes" and distilled water, oxidized and pre-electrolyzed to remove impurities, then supplemented with a dispersion of particles and additional components. The GRN additive was used as the anti-pitting and leveller component. To produce the graphene dispersion, two surface active substances were used: Z1 - fluorinated surfactant and Z2 - [3-(heptadekafluorineoctyl)-sulphonyl]-aminopropyl-trimethylammonium jodide. Composite coatings and the nickel coating were deposited at a $\mathrm{pH}$ 4 , in a temperature of $318 \mathrm{~K}$ and with a current density of $4 \mathrm{~A} / \mathrm{dm}^{2}$ during 30 minutes using a magnetic stirrer with a rotational speed of $100 \mathrm{rev} / \mathrm{min}$.

The anode was a nickel sheet with a surface twice as large. The substrate was prepared in the following manner:

- Degreasing with Vienna lime and etching with 1:1 hydrochloric acid (for corrosion resistance and roughness testing).

- Passivation with a $10 \%$ solution of sodium dichromate to permit the removal of deposited coating (for particle content testing).

\section{Measurement methodology}

Raman analysis was made using a Raman spectrometer (laser with an excitation wavelength of $532 \mathrm{~nm}$ ). The content of the dispersion particles in the composite coating was determined by titration. Thickness control of produced layers was performed by making cross sections on Struers device. Etched metallographic samples were observed under a Nikon Eclipse JV 150 optical microscope. The images of deposited coatings surfaces were recorded using a metallographic microscope. Scanning electron microscope combined with EDX (Hitachi S$-3400 \mathrm{~N}$ ) were used to analyse the surface morphology of the fabricated samples.

Internal stresses were measured using the dilatometric method ${ }^{24}$ with an IS-meter by OMI International, Austria. Internal stresses were expressed in MPa using a simplified formula:

$\sigma=-\frac{E_{0} \cdot t_{0} \cdot \lambda}{2 l_{0} \cdot t}$

where: $s$ - internal stresses in coating, $[\mathrm{MPa}] ;-l$ - change of sample length, $[\mathrm{mm}] ; l_{0}$ - length of coating in sample, $[\mathrm{mm}] ; t_{0}$ - thickness of base metal, [mm]; $E_{0}$ - elastic modulus of substrate, [199.3 GPa]; $t$ - coating thickness [mm].

Nickel and composite coatings were deposited on an Armco iron substrate measuring 250 × $10 \times 0.09 \mathrm{~mm}$. The overlay length of the nickel coating was $160 \mathrm{~mm}$.

Corrosion resistance was measured using the voltametric method with a three-electrode system. The reference electrode was chloride-silver electrode, the auxiliary electrode was platinum electrode. The working 
surface of the electrode subjected to corrosion testing was $1 \mathrm{~cm}^{2}$ and the test temperature was $20 \pm 2^{\circ} \mathrm{C}$. The basic element of the measurement setup was a computer-controlled Atlas 98 potentiostat by Sollich. Data control, collection, graphic and quantitative analysis were performed with POL-99 software. Potential variation speed was $1 \mathrm{mV} / \mathrm{s}$. Testing was carried out in a $0.5 \mathrm{M}$ non-deoxygenated sodium chloride solution with a $\mathrm{pH} 7$. The $\mathrm{i}=\mathrm{f}(\mathrm{E})$ curves were recorded within a range of $\pm 0.3 \mathrm{~V}$ of the stationary potential. The obtained Tafel curves were used to calculate the corrosion current and potential, and corrosion rate.

The microhardness of the deposited coatings was measured on the cross section by a Vivkers microhardness tester under the load of $0.01 \mathrm{kG}$.

\section{RESULTS AND DISCUSSION}

The nickel-graphene composite coatings were produced by electrochemical reduction method with two different surface-active substances. The amount 0.33 , 0.5 and $1 \mathrm{~g} / \mathrm{dm}^{3}$ graphene particles were used for the production of composite coatings. Figure 2 shows the measurement results of the contents of dispersed particles (IGP2 graphene) in nickel-graphene composite coatings. The increase in the content of dispersive particles in the bath with the addition of surfactant $\mathrm{ZB}$ caused a rise in their content in composite nickel-graphene coatings Cp from 3.5 to $12.8 \%$ by volume. On the other hand, in bath containing compound $\mathrm{ZA}$, caused a tendency to decrease content $\mathrm{Cp}$ from 6.6 to $4.3 \%$ by volume, in the bath concentration range from 0.33 to $0.5 \mathrm{~g} / \mathrm{dm}^{3}$. But further increase in bath concentration resulted in an increase in $\mathrm{Cp}$ to $12.5 \%$ vol. The amount of particles in the solution has significant effect on the percentage volume fraction of the particles incorporated into the metal matrix ${ }^{25}$. The influences of surfactants sodium dodecylsulfate (SDS) and hexadecyltrimethylammonium bromide (CTAB) on electrodeposition of Nicarbon nanotubes (CNTs) composite coatings were studied, in Watts bath. The results indicated that SDS in the bath slightly decreased but CTAB increased the codeposited CNTs content in the coatings. In solutions containing SDS, the anionic functional groups may be adsorbed on surface of CNTs, and these CNTs are excluded by the cathode. Hence the CNTs content into the coating may decrease. On the contrary, the surfactant CTAB may make the surface of CNTs be charged with cations, and these charged CNTs prefer to be adsorbed on the

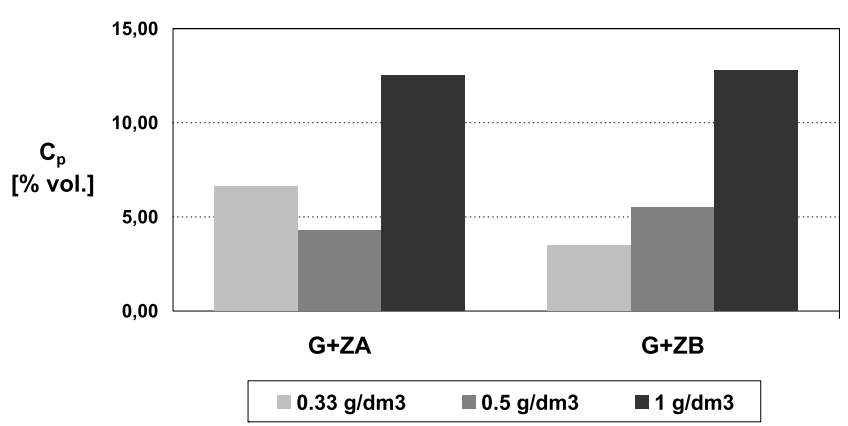

Figure 2. Dependence of graphene particles content in composite coatings on the concentration and kind of organic additives cathode. As a result, more CNTs are incorporated into the coatings during electrodeposition ${ }^{\mathbf{2 6}}$.

Figure 3 presents the cross-section image of obtained nickel-graphene coating from bath containinig $0.33 \mathrm{~g} / \mathrm{dm}^{3}$ graphene and organic compound ZA. A microscopic picture of the coating with the visible conglomerated flakes of graphene in nickel matrix is shown. The photography of surface coating achieved with a metallographic microscope for the same sample is represents in Figure 4.

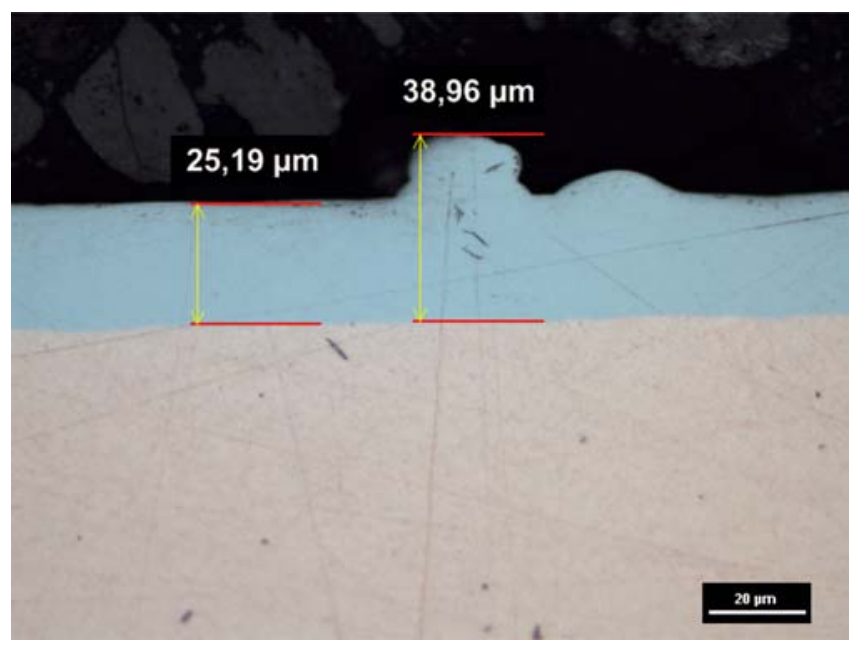

Figure 3. Cross section of nickel-graphene composite coating. (G $\left.0.33 \mathrm{~g} / \mathrm{dm}^{3}+\mathrm{ZA}\right)$

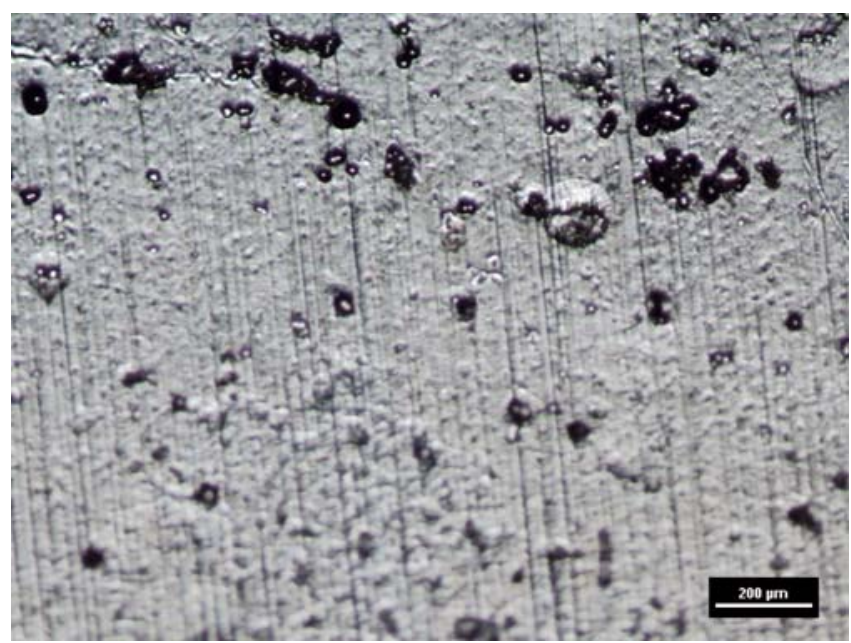

Figure 4. Image of a nickel-graphene composite coating. Metalographic microscope. (G $0.33 \mathrm{~g} / \mathrm{dm}^{3}+\mathrm{ZA}$ )

The SEM images of the nickel-graphene composite coating are given in Figure 5 and 6 . Figure 5 and 6 display the morphology of the nickel-graphene coating produced from plating bath containing $0.5 \mathrm{~g} / \mathrm{dm}^{3}$ graphene and surface-active compounds ZB. Graphene particle in composite coating is visible. Figure 7 and 8 show the EDS spectra of the selected area in Figure 6. The EDS analysis, in the specified areas marked on image surface, confirmed the presence of graphene in nickel matrix (Figs. 7, 8).

The dependence of internal stress on the thickness of coatings deposited from the bath containing graphene, GRN and surfactant ZA and ZB is presented in Figure 9. Internal stress of the deposited composite coatings depended to a large extent on the additive of 


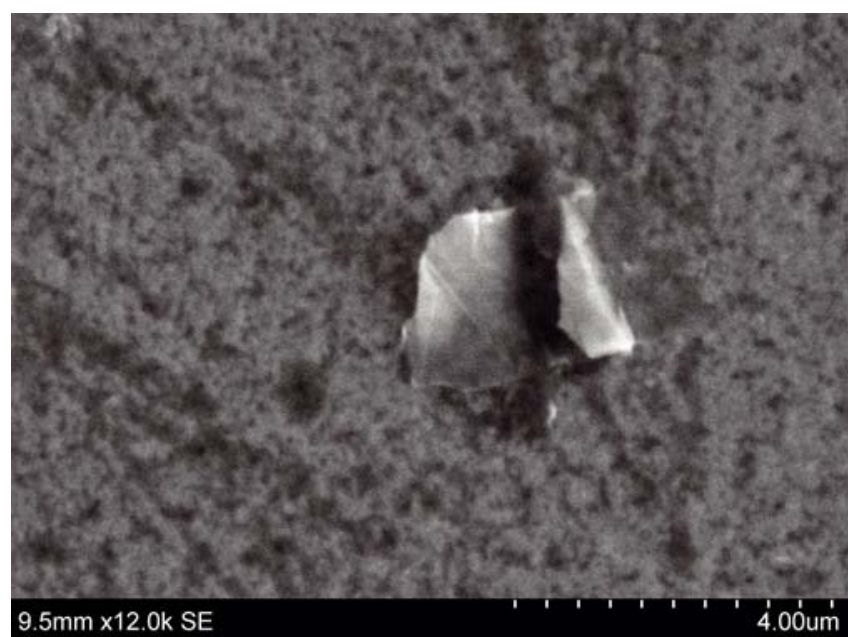

Figure 5. SEM image of a nickel-graphene coating. (G $0.5 \mathrm{~g}$ / $\left.\mathrm{dm}^{3}+\mathrm{ZB}\right)$.

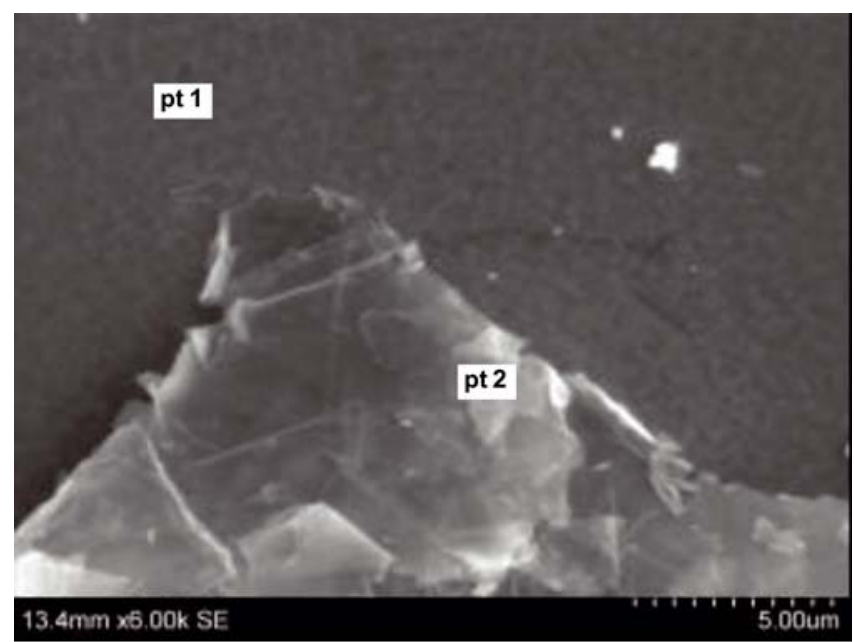

Figure 6. SEM image of a nickel-graphene coating with marked spectra EDS points. $\left(\mathrm{G} 0.5 \mathrm{~g} / \mathrm{dm}^{3}+\mathrm{ZB}\right)$

surfactants in the bath. The internal stress in the nickel-graphene composite coatings was compressive in the analyzed thickness range and hesitated from -500 to $-91 \mathrm{MPa}$. Stabilization of the stress of electrodeposited coatings was observed from a thickness $15 \mathrm{~mm}$. The ZB surfactant caused a reduction of compressive stress in comparison with those coatings which were deposited with ZA additive. For a thickness of $30 \mathrm{~mm}$, the application of graphene together with surfactant $\mathrm{ZA}$ or $\mathrm{ZB}$ caused that the coatings obtained with their presence exhibited slightly less compressive stress than for nickel coating. The applications of organic addition agents was advantageous. The results obtained are consistent with the data by Szeptycka ${ }^{24}$.

The corrosion resistance properties of nickel-graphene composite coatings were evaluated with intention

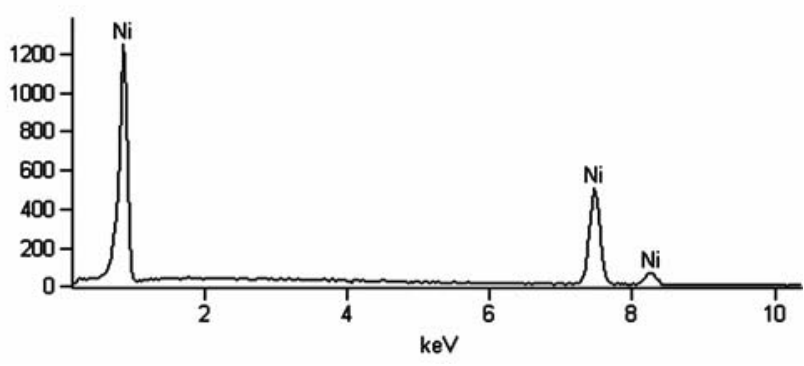

Figure 7. EDS spectrum of the surface in Figure 6 in the point 1. $\left(\mathrm{G} 0.5 \mathrm{~g} / \mathrm{dm}^{3}+\mathrm{ZB}\right)$

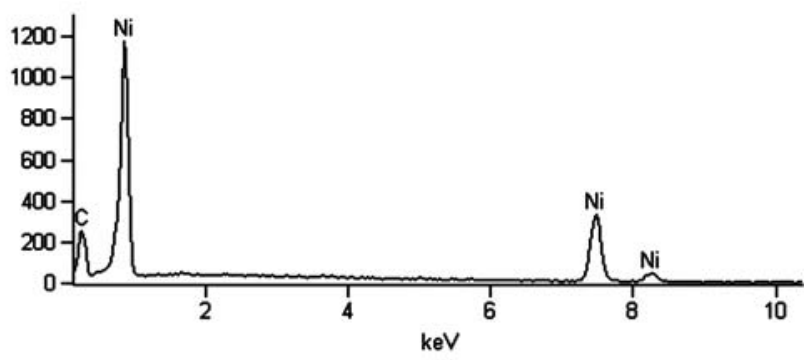

Figure 8. EDS spectrum of the surface in Figure 6 in the point 2. $\left(\mathrm{G} 0.5 \mathrm{~g} / \mathrm{dm}^{3}+\mathrm{ZB}\right)$

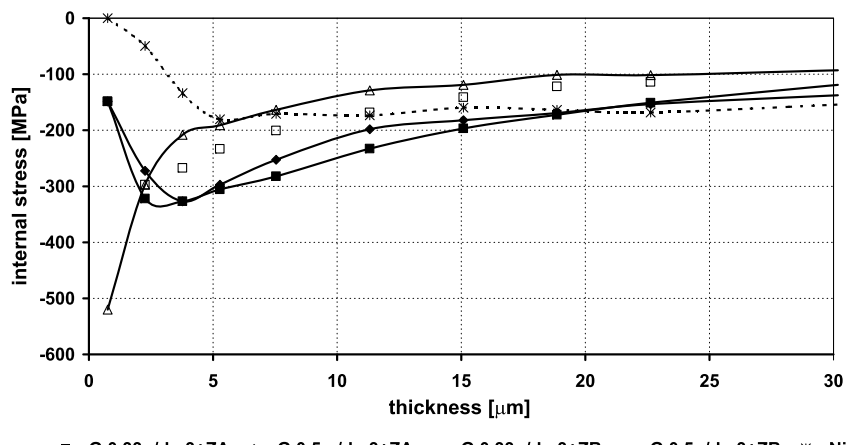

Figure 9. Internal stress of the nickel-graphene coatings deposited from the bath containing, graphene, GRN and surfactants ZA, ZB. For comparison a nickel coating without graphene

to obtain data concerning the protection ability of the coatings in $0.5 \mathrm{M} \mathrm{NaCl}$ corrosive media. The corrosion resistance of nickel and nickel-graphene coatings are given in Table 2. The nickel coating was deposited from a low concentration bath with GRN. Table 2 presents bath compositions, potential and corrosion current, corrosion rate in a $0.5 \mathrm{M} \mathrm{NaCl}$. The corrosion rate is decreased in nickel-graphene coatings compared to nickel coating. The highest resistance to corrosion in $0.5 \mathrm{M} \mathrm{NaCl}$ solution was achieved for a coating obtained from a bath with a $0.33 \mathrm{~g} / \mathrm{dm}^{3}$ graphene content with ZB surfactant. This

Table 2. Results of potential and corrosion current, corrosion rate in $0.5 \mathrm{M} \mathrm{NaCl}$ and microhardness $\mathrm{HV} 0.01$. Baths with the addition of graphene, GRN and surfactant ZA or ZB

\begin{tabular}{|c|c|c|c|c|}
\hline Bath composition & $\begin{array}{l}\text { Corrosion } \\
\text { potential } \\
\mathrm{E}_{\text {corr }} \\
{[\mathrm{V}]} \\
\end{array}$ & $\begin{array}{c}\text { Corrosion current } \\
\text { density } \\
J_{\text {corr }} \\
{\left[\mu \mathrm{A} / \mathrm{cm}^{2}\right]}\end{array}$ & $\begin{array}{c}\text { Corrosion rate } \\
r_{\mathrm{i}} * 10^{-3} \\
{[\mathrm{~mm} / \text { year }]}\end{array}$ & $\begin{array}{c}\text { Microhardness } \\
\qquad \mathrm{HV}_{0.01} \\
{[\mathrm{GPa}]}\end{array}$ \\
\hline G $0.33 \mathrm{~g} / \mathrm{dm}^{3}+\mathrm{ZA} 11 \mathrm{~cm}^{3} / \mathrm{dm}^{3}$ & -200 & 0.60 & 7.41 & 4.6 \\
\hline $\mathrm{G} 0.5 \mathrm{~g} / \mathrm{dm}^{3}+\mathrm{ZA} 16 \mathrm{~cm}^{3} / \mathrm{dm}^{3}$ & -225 & 0.66 & 8.12 & 5.0 \\
\hline $\mathrm{G} 0.33 \mathrm{~g} / \mathrm{dm}^{3}+\mathrm{ZB} 14 \mathrm{~cm}^{3} / \mathrm{dm}^{3}$ & -235 & 0.35 & 4.26 & 4.9 \\
\hline $\mathrm{G} 0.5 \mathrm{~g} / \mathrm{dm}^{3}+\mathrm{ZB} 21 \mathrm{~cm}^{3} / \mathrm{dm}^{3}$ & -220 & 0.50 & 6.16 & 4.6 \\
\hline $\mathrm{Ni}$ & -233 & 0.85 & 10.45 & 2.6 \\
\hline
\end{tabular}


coating corrosion rate was 2.5 times slower than in the case of a nickel coating without these additives. The corrosion rate was comparable to the data obtained by Kumar et al. ${ }^{16}$. Polarisation curves of coatings are shown in Figure 10. It can be clearly noticed that the addition of graphene particles improves the corrosion properties of nickel-graphene coatings as the value of $\mathrm{E}_{\text {corr }}$ is less negative and the corrosion current $\mathrm{I}_{\text {corr }}$ is lower on the nickel-graphene composite coatings as compared to nickel coating. This improvement in corrosion behavior can be attributed to the reduction in active area of nickel matrix which is more available to the corrosive environment.

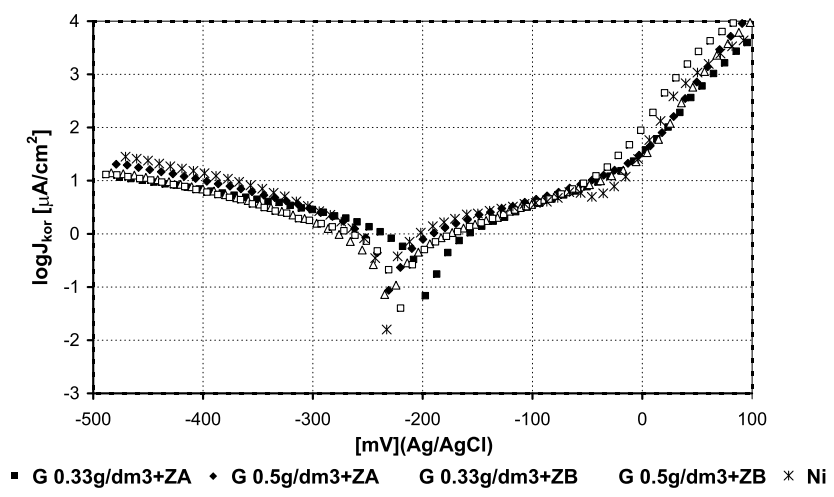

Figure 10. Polarization curves in $0.5 \mathrm{M} \mathrm{NaCl}$. Nickel-graphene composite coatings deposited from a bath with the addition of graphene, GRN and surfactant ZA or ZB. For comparison a nickel coating without graphene

In this work the thickness of all deposited coatings in places without conglomerates were from 22 to $25 \mu \mathrm{m}$. The thickness of the $\mathrm{Ni}$-graphene composite coatings were increased from 15 to $50 \mu \mathrm{m}$ with the increasing of electrodeposition temperature ${ }^{\mathbf{1 9}}$. There are several factors accountable for improved and decreased corrosion resistance at different thickness. Firstly, the uniformly distributed graphene sheets filled the micron holes, crevices and gaps in the nickel matrix, homogeneous dispersion of graphene during the deposition process and inert physical barrier property of graphene are responsible for improved corrosion resistance. Secondly, when the thickness increases, fine cracks appeared on the surface of coatings and some hydrogen atoms absorber on the coatings surface and diffused inside the deposited coatings and in result residual stress appeared, so decreased in corrosion resistance ${ }^{19}$.

The microhardness HV 0.01 of the nickel-graphene coatings deposited from the bath containing surfactants $\mathrm{ZA}$ or ZB was between 4.6 and 5.0 GPa (Table 2). The composite coatings showed greater microhardness than of nickel coating. The higher microhardness of nickel-graphene coatings was due to the inclusion of graphene particles in the nickel matrix. The improvement in the microhardness of composite coatings is related to the dispersion hardening effect caused by graphene particles in the matrix, which obstructs the shift of dislocation in nickel matrix. In the study, the effect of surfactant ZA and $\mathrm{ZB}$ on microhardness was different The hardness of composite films deposited in the presence of surfactant ZA increased with the increase of the content of the graphene in the bath and decreased for $\mathrm{ZB}$. Gul et al. ${ }^{27}$ shows the effect of concentration of HPB on the microhardness of $\mathrm{Ni}-\mathrm{Al}_{2} \mathrm{O}_{3}$ composite coatings. There is an increasing trend of the microhardness of composite coatings till the concentration of HPB $200 \mathrm{mg} / \mathrm{dm}^{3}$ after which the microhardness decreased.

\section{CONCLUSIONS}

The nickel-graphene composite coatings were successfully fabricated by electrodeposition method. The bath composition with surfactants affects the contents of dispersed particles (IGP2 graphene) in nickel-graphene composite coatings and their properties.

All analyzed nickel-graphene composite coatings featured compressive internal stresses and a better corrosion resistance than a nickel coating.

\section{LITERATURE CITED}

1. Łosiewicz, B. (2015). The role of $\mathrm{Ni}(\mathrm{II})$ ion adsorption onto $\mathrm{TiO}_{2}$ in the electrodeposition of composite $\mathrm{Ni}-\mathrm{P}+\mathrm{TiO}_{2}$ coatings. Solid State Phenomena. 228, 89-100. DOI: 10.4028/ www.scientific.net/SSP.228.89

2. Szeptycka, B. \& Gajewska, A. (2003). The structural and tribological properties of nanocrystalline electrochemical coatings with nickel matrix. Solid State Phenomena 94, 245-248.

3. Szeptycka, B. \& Gajewska-Midziałek, A., (2005). Investigations of the wear resistance of composite coatings Ni-SiC. Kompozyty 5, 2-7.

4. Gajewska-Midziałek, A., Szeptycka, B., Derewnicka, D. \& Nakonieczny, A. (2006). Wear resistance of nanocrystalline composite coatings. Tribology Int. 39(8), 763-768. DOI: 10.1016/j. triboint.2005.07.005.

5. Szeptycka, B., (2010). The nano - structured Ni-SiC coatings and their tribological properties. Engineering \& $\mathrm{Au}$ tomation Problems. 2, 117-120.

6. Benea., L., Bonora, A., Borello, A. \& Martelli, S. (2002). Effect of $\mathrm{SiC}$ size dimensions on the corrosion wear resistance of the electrodeposited composite coating. Mat. Corr. 53, 23-29.

7. Malfatti, C.F., Ferreira, J. Z., Santos, C.B., Souza, B.V., Fallavena, E.P., Vaillant, S. \& Bonino, J.P. (2005). NiP/SiC composite coatings: the effects of particles on the electrochemical behavior. Corr. Sci. 47, 567-580. DOI: 10.1016/j. corsci.2004.07.011.

8. Gladkovas, M., Medeliene, V., Samuleviciene, M. \& Juzeliunas E. (2002). Corrosion study of electroplated nickel-matrix composites with $\mathrm{B}_{4} \mathrm{C}, \mathrm{Al}_{2} \mathrm{O}_{3}$ and SiC. Chemija 13(1), 36-40.

9. Szczygieł, B. \& Kołodziej, M. (2005). Corrosion resistance of $\mathrm{Ni} / \mathrm{Al}_{2} \mathrm{O}_{3}$ coatings in $\mathrm{NaCl}$ solution. Trans. Inst. Metal Finish 83(4), 181-187. DOI: org/10.1179/002029605X61658

10. Wan, X., Xu, Y., Guo, H., Shehzad, K., Ali, A., Liu, Y., Yang, J., Dai, D., Lin, C.-T., Liu, L., Cheng, H.-C., Wang, F., Wang, X., Lu, H., Hu, W., Pi, X., Dan, Y., Luo, J., Hasan, T., Duan, X., Li, X., Xu, J., Yang, D., Ren, T. \& Yu, B. (2017). A self-powered high-performance graphene/silicon ultraviolet photodetector with ultra-shallow junction: breaking the limit of silicon? Nat. Part. J. 2 D Mater Appl. 4, 1-8. DOI:10.1038/ s41699-017-0008-4.

11. Xu, Y., Ali, A., Shehzad, K., Meng, N., Xu, M.S., Zhang, Y.H., Wang, X. R., Jin, C. H., Wang, H.T., Guo, Y.Z., Yang, Z.Y., Yu, B., Liu, Y., He, Q.Y., Duan, X.F., Wang, X.M., Tan, P.H., Hu, W.D., Lu, H. \& Hasan, T. (2017). Solvent-based soft-patterning of graphene lateral heterostructures for broadband high-speed metal-semiconductor-metal photodetectors. $A d v$. Mater. Technol. 2(2), 1600241.

12. Du, S., Lu, W., Ali, A., Zhao, Z., Shehzad, K., Guo, H., Ma, L., Liu, X., Pi, X., Wang, P., Fang, H., Xu, Z., Gao, Ch., Dan, Y., Tan, P., Wang, H., Lin, Ch-T., Yang, J., Dong, S., Cheng, Z., Li, E., Yin, W., Luo, J., Yu, B., Hasan, T., Xu, Y., 
Hu, W. \& Duan, X. (2017). A broadband fluorographene photodetector. Adv. Mater. 29, 1-8. DOI: 10.1002/adma.201700463

13. Shehzad, K., Shi, T., Qadir, A., Wan, X., Guo, H., Ali, A., Xuan, W., Xu, H., Gu, Z., Peng, X., Xie, J., Sun, L., He, Q., Xu, Z., Gao, C., Rim, Y.-S., Dan, Y., Hasan, T., Tan, P., Li, E., Yin, W., Cheng, Z., Yu, B., Xu, Y., Luo, J. \& Duan, X. (2017). Designing an efficient multimode environmental sensor based on graphene-silicon heterojunction. Adv. Mater. Technol. 2(4), 1600262. DOI: 10.1002/admt.201600262.

14. Wang, D., Yan, W., Vijapur, S.H. \& Botte, G.G. (2013). Electrochemically reduced graphene oxide-nickel nanocomposites for urea electrolysis. Electrochim. Acta 89, 732-736. DOI: 10.1016/j.electacta.2012.11.046.

15. Kuang, D., Xu, L., Liu, L., Hu, W. \& Wu, Y. (2013). Graphene-nickel composites. Appl. Surf. Sci. 273, 484-490. DOI: 10.1016/j.apsusc.2013.02.066.

16. Kumar, C.M.P., Venkatesha, T.V. \& Shabadi, R. (2013). Preparation and corrosion behavior of $\mathrm{Ni}$ and $\mathrm{Ni}$-graphene composite coatings. Mater. Res. Bull. 48, 1477-1483. DOI: 10.1016/j.materresbull.2012.12.064.

17. Jiang, K., Li, J. \& Liu, J. (2014). Electrochemical codeposition of graphene platelets and nickel for improved corrosion resistant properties. RSC Adv. 4, 36245-36252.

18. Ren, Z., Meng, N., Shehzad, K., Xu, Y., Qu, S., Yu, B. \& Luo, J.K. (2015). Mechanical properties of nickel-graphene composites synthesized by electrochemical deposition. Nanotechnology. 26(6), 065706.

19. Jabbar, A., Yasin, G., Khan, W.Q., Anwar, M.Y., Korai, R.M., Nizam, M.N. \& Muhyodin, G. (2017). Electrochemical deposition of nickel graphene composite coatings: effect of deposition temperature on its surface morphology and corrosion resistance. Royal Soc. Chem. Adv. 7, 31100-31109. DOI: $10.1039 / \mathrm{c} 6 \mathrm{ra} 28755 \mathrm{~g}$.

20. Huang, X., Qi, X., Boey, F. \& Zhang, H. (2012). Graphene-based composites. Chem. Soc. Rev. 41, 666-686. DOI: 10.1039/c1cs15078b.

21. Woźniak, J.T., Trzaska, M., Cieślak, G., Cygan, T., Kostecki, M. \& Olszyna, A. (2016). Preparation and mechanical properties of alumina composites reinforced with nickel-coated graphene. Ceramics Int. 42, 8597-8603. DOI: 10.1016/j. ceramint.2016.02.089.

22. Grodecki, K. (2013). Spektroskopia ramanowska grafenu. Mater. Elektron. 41(1), 47-53.

23. Ferrari, A., (2007), Raman spectroscopy of graphene and graphite: Disorder, electron-phonon coupling, doping and nonadiabatic effects. Solid State Commun. 143, 47-57.DOI: 10.1016/j.ssc.2007.03.052.

24. Szeptycka, B. (2009). Naprężenia własne galwanicznych powłok niklowych. Część 2. Wpływ cząstek dyspersyjnych i związków organicznych na naprężenia własne kompozytowych powłok niklowych. The internal stresses of the galvanic nickel coatings. Part 2. Influence of the dispersion particles and the organic compounds on the internal stresses of the composite nickel coatings. Inż.Powierzchni 1, 46-53.

25. Low, C.T.J., Wills, R.G.A. \& Walsh, F.C. (2006). Electrodeposition of composite coatings containing nanoparticles in a metal deposit. Surf. Coat. Technol. 201, 371-383. DOI: 10.1016/j.surfcoat.2005.11.123.

26. Guo, Ch., Zuo, Y., Zhao, X., Zhao, J. \& Xiong, J. (2008). Effects of surfactants on electrodeposition of nickel-carbon nanotubes composite coatings. Surf. Coat. Technol. 202, 3385-3390. DOI: 10.1016/j.surfcoat.2007.12.005.

27. Gul, H., Kilic, F., Aslan, S., Alp, A. \& Akbulut, H. (2009). Characteristics of electro-co-deposited $\mathrm{Ni}-\mathrm{Al}_{2} \mathrm{O}_{3}$ nano-particle reinforced metal matrix composite (MMC) coatings. Wear 267, 976-990. DOI: 10.1016/j.wear.2008.12.022. 